\title{
Injury patterns of South African provincial cricket players over two seasons
}

\author{
Richard A Stretch (DPhil) \\ Ryan P Raffan (BA, HMS Hons) $)^{2}$ \\ Nicole Allan (BA, HMS Hons) ${ }^{2}$ \\ ${ }^{1}$ Sport Bureau, Nelson Mandela Metropolitan University, Port Elizabeth \\ ${ }^{2}$ Department of Human Movement Science, Nelson Mandela Metropolitan University, Port Elizabeth
}

\begin{abstract}
Objective. To determine the incidence and nature of injury patterns in elite cricketers over two seasons.

Methods. Physiotherapists and/or doctors working with 4 provincial teams completed a questionnaire for each cricketer who presented with an injury during the $2004-2005\left(S_{1}\right)$ and 2005 - $2006\left(S_{2}\right)$ cricket seasons. This was done to determine: $(i)$ the anatomical site of injury; (ii) the month of injury during the season; (iii) the diagnosis using the OSCIS injury classification system; (iv) the mechanism of injury; $(v)$ whether it was a recurrence of a previous injury; (vi) whether the injury had recurred again during the season; and (vii) biographical data.

Results. The results showed that 180 injuries $\left(S_{1}-84 ; S_{2}-96\right)$ were sustained. On average the teams spent 2472 hours on matches, 4148 on practices and 1612 on fitness training during the two-season period. The injury prevalence was $8 \%$ per match, while the injury incidence was 30/10 000 hours of match, practice and training time, with the match incidence being 74 injuries/ 10000 hours and the training incidence 15 injuries/10 000 hours. Bowling (29\%), fielding and wicket-keeping (27\%) and batting $(19 \%)$ accounted for the majority of injuries. The occurrence of injuries was predominantly to the lower limbs $\left(S_{1}-45 \% ; S_{2}-42 \%\right)$, back and trunk $\left(S_{1}-19 \% ; S_{2}-19 \%\right)$, upper limbs $\left(S_{1}-19 \%\right.$; $\left.S_{2}-22 \%\right)$, head and neck $\left(S_{1}-6 \% ; S_{2}-3 \%\right)$, and related to illnesses $\left(S_{1}-11 \% ; S_{2}-14 \%\right)$. The injuries occurred primarily during first-class matches (39\%), limited-overs matches $(22 \%)$, and practices $(17 \%)$, and some were of gradual onset $(20 \%)$. Acute injuries comprised $78 \%$ of injuries. The majority of injuries were first-time injuries ( $76 \%$ ), with $11 \%$ and $14 \%$ recurrent injuries from the previous and current seasons, respectively. The
\end{abstract}

\section{CORRESPONDENCE:}

Dr Richard Stretch

Nelson Mandela Metropolitan University

PO Box 77000

Port Elizabeth, 6031

South Africa

E-mail: richard.stretch@nmmu.ac.za major injuries during $\mathrm{S}_{1}$ were haematomas $(19 \%)$, muscle strains $(17 \%)$ and other trauma (14\%), while during $S_{2}$ the injuries were primarily muscle strains $(16 \%)$, other trauma $(20 \%)$, tendinopathy $(16 \%)$ and acute sprains $(15 \%)$. The primary mechanisms of injury occurred in the delivery stride when bowling $(19 \%)$ and overbowling $(7 \%)$, on impact by the ball when batting $(11 \%)$, and on sliding to field the ball $(6 \%)$.

Conclusion. The results indicate a pattern of cause of injury, with the fast bowler most likely to sustain an acute injury to the soft tissues of the lower limb while participating in matches and practices during the early part of the season.

\section{Introduction}

Long-term injury surveillance has been carried out in Australia, South Africa and England to identify injury patterns. Retrospective injury information was obtained from 54 cricketers who had played for the same county first team in England between 1985 and 1995, with 990 injuries indicating an injury exposure of 17247 days played and an injury incidence rate of $57 / 1000$ days played. ${ }^{1}$ Most injuries were sustained early in the season. Bowlers were most susceptible to injury (70/1 000 days), followed by all-rounders, batsmen and wicketkeepers with 55, 49 and 47 injuries per 1000 days, respectively. Most injuries occurred to the lower limbs $(45 \%)$, with muscle/tendon strains, contusions/haematomas, and ligament/joint sprains being the most common. The most vulnerable sites for injury were the thigh and calf $(25 \%)$, fingers (14\%) and lumbar spine $(11 \%)$.

The study in South Africa ${ }^{2}$ prospectively recorded 1606 injuries in 783 national and provincial cricketers over a six-season period from 1998 - 1999 to 2003 - 2004. More injuries occurred during first-class matches $(32 \%)$, with limited-overs matches $(26 \%)$ and practices and training $(27 \%)$ resulting in a similar number of injuries, while $15 \%$ were of gradual onset. The chronicity of injuries showed that the majority were classified as acute $(65 \%)$, with chronic $(23 \%)$ and acute-on-chronic $(12 \%)$ comprising the balance. First-time injuries accounted for $65 \%$, while the balance of injuries were from the previous season $(22 \%)$ and from those recurring again during the same season (12\%). Bowling (40\%) accounted for the majority of injuries, with $55 \%$ of these being lower-limb injuries and $33 \%$ back and trunk injuries. Of the 39 stress fractures, $79 \%$ were as a result of overuse in bowlers. The primary mechanism of injury was the delivery and follow-through of the fast bowler $(25 \%)$, running, diving, catching and throwing the ball when fielding $(23 \%)$, overuse $(17 \%)$, 
various batting situations such as being struck while batting $(7 \%)$, running between the wickets (4\%), batting for long periods at a time $(4 \%)$, training $(4 \%)$, and participating in various other sports $(3 \%)$.

Injury data of Australian state and national cricketers were collected retrospectively for the first three seasons (1995 - 1996 to 1997 - 1998) and then prospectively for the next six seasons (1999 - 2000 to $2004-2005){ }^{3}$ Of the 886 injuries recorded, $92 \%$ were new, $8 \%$ were recurrent, and $52 \%$ occurred during major matches. The injuries were mainly sustained while bowling (45\%), with lowerlimb injuries accounting for $49 \%$. The mean seasonal injury match incidence was reported for domestic one-day (39/10 000 playerhours), first-class (27/10 000 player-hours), one-day international (ODI) (60/10 000 player-hours) and test (39/10 000 player-hours) matches. Fast bowlers miss about $16 \%$ of potential playing time because of injury, while for other positions it is less than $5 \%$.

The first study to use the international surveillance method ${ }^{4}$ reported that 162 domestic and 33 international cricketers sustained 50 injuries. Most injuries were sustained in test and first-class matches (40\%), with a further $28 \%$ occurring during one-day matches and other activities outside of matches. The injury incidence for tests and ODI matches was 49 and 41 injuries/10 000 player-hours, respectively. For domestic first-class and limited-overs matches it was 14 and 25 injuries/10 000 player-hours, respectively. The injury prevalence for test $(11 \%)$ and ODI (8\%) matches was lower for home matches than away matches. Bowlers (46\%) and batsmen (40\%) were at greatest risk of injury, with muscles $(26 \%)$ and ligament $(12 \%)$ injuries, stress fractures (12\%) and fractures (10\%) being most common. Most of the injuries were new $(80 \%)$, with $10 \%$ recurrent from the previous season and $10 \%$ recurring again during the same season.

All the injury surveillance studies, with the exception of the study carried out on West Indian cricketers, ${ }^{4}$ were carried out before the international acceptance of the publication of the consensus paper regarding injury definitions, methods of calculating injury rates and reporting of injuries. ${ }^{2}$ Therefore, the aim of this study was to use the internationally agreed methods for injury surveillance to investigate the seasonal incidence and nature of injuries sustained by South African provincial cricketers to further understand and identify injury patterns, risk factors and other possible factors associated with these injuries.

\section{Methods}

During the $2004-2005\left(S_{1}\right)$ and $2005-2006\left(S_{2}\right)$ cricket seasons, matches played by 4 of the 6 provincial teams were monitored prospectively. Data were collected and reported according to the guidelines in the consensus paper. ${ }^{5}$ The physiotherapists working with the teams were required to complete a questionnaire for all cricketers who presented with an injury. The questionnaire was designed to obtain the following information: (i) biographical data; (ii) month of injury during the season; (iii) activity and time of onset of injury; (iv) whether it was a first-time injury or a recurrent injury from the previous or current season; (v) chronicity of the injury; (vi) whether the injury had recurred again during the season; (vii) the $\mathrm{OSCIS}^{6}$ injury classification code; (viii) diagnosis; and (ix) mechanism of injury. Further, to determine player exposure it was necessary to collect information on a player's participation in each match, reasons for non-participation, and length of the match. ${ }^{2}$

For the purpose of this research an injury was defined as any injury or other medical condition that either: (i) prevents a player from being fully available for selection for a major match; or (ii) during a major match causes a player to be unable to bat, bowl or keep wicket when required to do so by either the rules or the team's captain. ${ }^{5}$ Acute injuries were those of rapid onset, and chronic injuries were

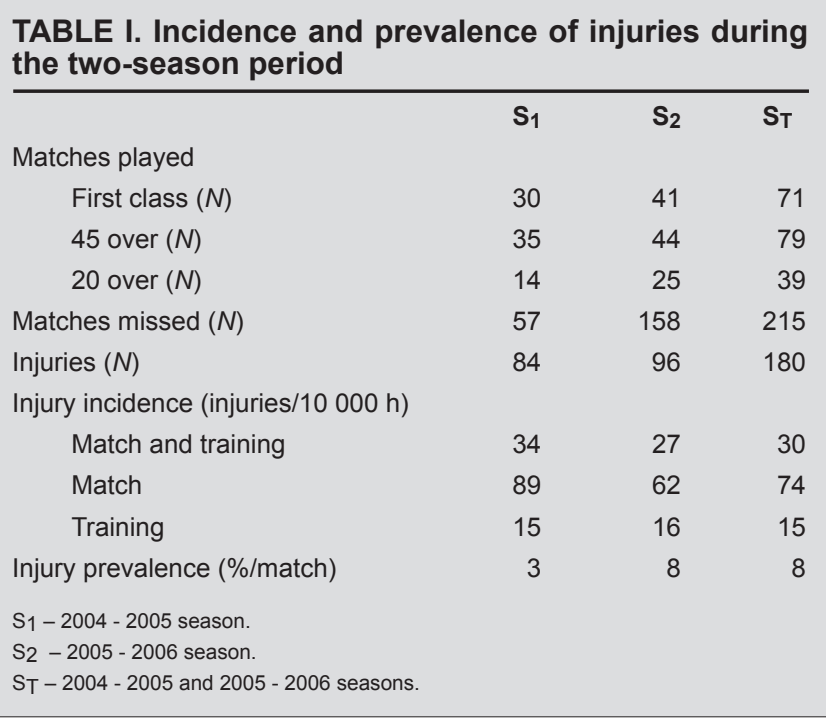

TABLE III. Number of injuries sustained in matches, practices and training during the two-season period

\begin{tabular}{|c|c|c|c|c|c|c|}
\hline & \multicolumn{2}{|c|}{$s_{1}$} & \multicolumn{2}{|c|}{$S_{2}$} & \multicolumn{2}{|c|}{$\mathrm{S}_{\mathbf{T}}$} \\
\hline & $N$ & $\%$ & $N$ & $\%$ & $N$ & $\%$ \\
\hline \multicolumn{7}{|l|}{ Matches } \\
\hline 20 over & 1 & 1 & 7 & 7 & 8 & 4 \\
\hline 45 over & 13 & 16 & 18 & 19 & 31 & 17 \\
\hline First class & 42 & 50 & 28 & 29 & 70 & 39 \\
\hline Practice & 14 & 17 & 16 & 17 & 30 & 17 \\
\hline Gradual onset & 12 & 14 & 23 & 24 & 35 & 20 \\
\hline Training & 2 & 2 & 4 & 4 & 6 & 3 \\
\hline Total & 84 & 100 & 96 & 100 & 180 & 100 \\
\hline \multicolumn{7}{|c|}{$\begin{array}{l}\mathrm{S}_{1}-2004-2005 \text { season. } \\
\mathrm{S}_{2}-2005 \text { - } 2006 \text { season. } \\
\text { ST }-2004 \text { - } 2005 \text { and } 2005 \text { - } 2006 \text { seasons. } \\
\text { Percentages have been rounded. }\end{array}$} \\
\hline
\end{tabular}

TABLE V. Diagnosis of injuries sustained during the twoseason period

\begin{tabular}{|c|c|c|c|c|c|c|}
\hline & \multicolumn{2}{|c|}{$\mathrm{S}_{1}$} & \multicolumn{2}{|c|}{$\mathrm{S}_{2}$} & \multicolumn{2}{|c|}{$\mathrm{S}_{\mathrm{T}}$} \\
\hline & $N$ & $\%$ & $N$ & $\%$ & $N$ & $\%$ \\
\hline Haematomas & 16 & 19 & 6 & 6 & 22 & 12 \\
\hline Acute sprains & 6 & 7 & 14 & 15 & 20 & 11 \\
\hline Tendinopathies & 4 & 5 & 15 & 16 & 19 & 11 \\
\hline Muscle strains & 14 & 17 & 15 & 16 & 29 & 16 \\
\hline Trauma & 12 & 14 & 19 & 20 & 31 & 17 \\
\hline Other injuries & 32 & 38 & 27 & 28 & 59 & 33 \\
\hline Total & 84 & 100 & 96 & 100 & 180 & 100 \\
\hline $\begin{array}{l}\mathrm{S}_{1}-2004-2005 \mathrm{se} \\
\mathrm{S}_{2}-2005-2006 \mathrm{se} \\
\mathrm{ST}-2004-2005 \mathrm{a} \\
\text { The percentages ha }\end{array}$ & $\begin{array}{l}05-2 \\
\text { en ro }\end{array}$ & sons. & & & & \\
\hline
\end{tabular}

of prolonged or extended onset, while acute-on-chronic injuries were increased symptoms of a chronic injury but brought about by movements causing rapid onset.

The time in the season when the injury occurred was recorded. Off-season was defined as that part of the season when no specific cricket practice or training took place. The pre-season, a 2-month 


\begin{tabular}{|c|c|c|c|c|c|c|}
\hline & \multicolumn{2}{|c|}{$s_{1}$} & \multicolumn{2}{|c|}{$S_{2}$} & \multicolumn{2}{|c|}{$\mathrm{S}_{\mathrm{T}}$} \\
\hline & $N$ & $\%$ & $N$ & $\%$ & $N$ & $\%$ \\
\hline First time & 66 & 79 & 70 & 73 & 136 & 76 \\
\hline \multicolumn{7}{|l|}{ Recurring } \\
\hline Previous season & & 7 & 13 & 14 & 19 & 11 \\
\hline Current season & 12 & 14 & 13 & 14 & 25 & 14 \\
\hline Acute & 68 & 81 & 72 & 75 & 140 & 78 \\
\hline Chronic & 6 & 7 & 8 & 8 & 14 & 8 \\
\hline Acute-on-chronic & 10 & 12 & 16 & 17 & 26 & 14 \\
\hline $\begin{array}{l}S_{1}-2004-2005 \text { season. } \\
S_{2}-2005-2006 \text { season. } \\
\text { ST - } 2004-2005 \text { and } 2005\end{array}$ & & & & & & \\
\hline
\end{tabular}

TABLE IV. Regional distribution of injuries sustained during the two-season period

\begin{tabular}{|c|c|c|c|c|c|c|}
\hline & \multicolumn{2}{|c|}{$\mathrm{S}_{1}$} & \multicolumn{2}{|c|}{$\mathrm{S}_{2}$} & \multicolumn{2}{|c|}{$\mathrm{S}_{\mathrm{T}}$} \\
\hline & $N$ & $\%$ & $N$ & $\%$ & $N$ & $\%$ \\
\hline Head and neck & 5 & 6 & - & - & 5 & 3 \\
\hline Upper limb & 16 & 19 & 24 & 25 & 40 & 22 \\
\hline Back and trunk & 16 & 19 & 18 & 19 & 34 & 19 \\
\hline Lower limb & 38 & 45 & 37 & 39 & 75 & 42 \\
\hline Other & 9 & 11 & 17 & 18 & 26 & 14 \\
\hline Total & 84 & 100 & 96 & 100 & 180 & 100 \\
\hline $\begin{array}{l}S_{1}-2004-2005 s e \\
S_{2}-2005-2006 s e \\
S_{T}-2004-2005 \text { ar } \\
\text { The percentages ha }\end{array}$ & 5 - 20 & sons. & & & & \\
\hline
\end{tabular}

period, was that part of the season when specific cricket practice and training were undertaken before the commencement of matches. The season was defined as that part of the season when matches were played and included international tours.

The BMDP Statistical Software Package (BMDP, 1993, Los Angeles, BMDP Statistical Software Inc.) was used to compute descriptive statistics

\section{Results}

The 4 provincial teams played a total of 71 first-class, 7945 -over and 3920 -over matches. One hundred and eighty injuries were reported over the two seasons $\left(S_{1}-84 ; S_{2}-96\right)$, which resulted in players missing 215 matches (Table I).

The injury incidence for the two seasons for the matches, practices and training was $30 / 10000$ hours, with the match incidence being $74 / 10000$ hours and the practice and training incidence being $15 / 10000$ hours. The injury prevalence increased from $S_{1}(3 \%)$ to $\mathrm{S}_{2}(8 \%)$ (Table I). Although more injuries occurred in $\mathrm{S}_{2}(53 \%)$ than $\mathrm{S}_{1}(47 \%)$, the number of matches missed owing to injuries increased from 57 to 158

First-time and acute injuries comprised $76 \%$ and $78 \%$ of the injuries to provincial players, respectively. The number of recurring injuries from the previous season increased from $S_{1}(7 \%)$ to $S_{2}$ $(14 \%)$ and was accompanied by an increase in acute-on-chronic injuries from $12 \%$ to $17 \%$ (Table II).

\begin{tabular}{|c|c|c|c|c|c|c|}
\hline & \multicolumn{2}{|c|}{$s_{1}$} & \multicolumn{2}{|c|}{$S_{2}$} & \multicolumn{2}{|c|}{$\mathbf{S}_{\mathrm{T}}$} \\
\hline & $N$ & $\%$ & $N$ & $\%$ & $N$ & $\%$ \\
\hline Batting & 18 & 21 & 16 & 17 & 34 & 19 \\
\hline Impact by ball & 14 & & 6 & & 20 & \\
\hline Batting - overuse & 4 & & 9 & & 13 & \\
\hline Other & - & & 1 & & 1 & \\
\hline Bowling & 28 & 33 & 25 & 26 & 53 & 29 \\
\hline Delivery stride & 9 & & 2 & & 11 & \\
\hline Over-bowling & 9 & & 4 & & 13 & \\
\hline General bowling & 6 & & 17 & & 23 & \\
\hline Other & 4 & & 2 & & 6 & \\
\hline Fielding & 21 & 25 & 27 & 28 & 48 & 27 \\
\hline Sliding for ball & 6 & & 5 & & 11 & \\
\hline Running to field bal & & & 4 & & 6 & \\
\hline Impact by ball & 6 & & 2 & & 8 & \\
\hline Catching a ball & 3 & & 3 & & 6 & \\
\hline Throwing & - & & 6 & & 6 & \\
\hline Other & 4 & & 7 & & 11 & \\
\hline Fitness & 2 & 3 & 3 & 3 & 5 & 3 \\
\hline Touch rugby & 1 & & 2 & & 3 & \\
\hline Other & 1 & & 1 & & 2 & \\
\hline Other & 15 & 18 & 25 & 26 & 40 & 22 \\
\hline IIIness & 8 & & 18 & & 26 & \\
\hline Other & 7 & & 7 & & 14 & \\
\hline Total & 84 & 100 & 96 & 100 & 180 & 100 \\
\hline $\begin{array}{l}\mathrm{S}_{1}-2004-2005 \text { season. } \\
\mathrm{S}_{2}-2005-2006 \text { season. } \\
\mathrm{ST}_{-} 2004-2005 \text { and } 200 \\
\text { The percentages have bee }\end{array}$ & $\begin{array}{l}5-20 \\
\text { en rou }\end{array}$ & & & & & \\
\hline
\end{tabular}

The injuries occurred primarily during matches $(61 \%)$, with the balance occurring as a result of gradual onset $(20 \%)$, practices (17\%) and training (3\%) (Table III). The regional distribution of injuries indicates that these were mainly to the lower limbs (42\%) (Table IV).

The major injury occurrences in $\mathrm{S}_{1}$ were haematomas (19\%), muscle strains $(17 \%)$ and trauma $(14 \%)$. Similar results were found for $S_{2}$, with the major injury categories being muscle strains (16\%), trauma $(20 \%)$, tendinopathies (16\%) and acute sprains (15\%) (Table V).

The majority of injuries occurred while bowling $(33 \%)$ in $\mathrm{S}_{1}$, with fielding $(25 \%)$ and batting (21\%) contributing to the remainder of the injuries (Table VI). In $\mathrm{S}_{2}$ the injuries were distributed more evenly among fielding (28\%), bowling (26\%), 'other' $(26 \%)$ and batting $(17 \%)$. The mechanisms for injuries within each activity are shown in Table VI. More injuries occurred during the first half of the season (October - December) than in the second half (January - March) (Table VII).

The mean match and practice exposure time increased from $\mathrm{S}_{1}(2096 \mathrm{~h})$ to $\mathrm{S}_{2}(2136 \mathrm{~h})$, while there was a decrease in fitness exposure time from $S_{1}(2013 \mathrm{~h})$ to $S_{2}(1714 \mathrm{~h})$ (Table VIII). Team 1 


\begin{tabular}{|c|c|c|c|c|c|c|}
\hline & \multicolumn{2}{|c|}{$S_{1}$} & \multicolumn{2}{|c|}{$S_{2}$} & \multicolumn{2}{|c|}{$\mathrm{S}_{\mathrm{T}}$} \\
\hline & $N$ & $\%$ & $N$ & $\%$ & $N$ & $\%$ \\
\hline Pre-season & - & - & - & - & - & - \\
\hline August & - & & - & & - & \\
\hline September & - & & - & & - & \\
\hline Season & 83 & 99 & 81 & 84 & 164 & 91 \\
\hline January & 10 & & 9 & & 19 & \\
\hline February & 7 & & 15 & & 22 & \\
\hline March & 16 & & 17 & & 33 & \\
\hline October & 10 & & - & & 10 & \\
\hline November & 21 & & 16 & & 37 & \\
\hline December & 19 & & 24 & & 43 & \\
\hline Off-season & 1 & 1 & 15 & 16 & 16 & 9 \\
\hline April & 1 & & 3 & & 4 & \\
\hline May & - & & 12 & & 12 & \\
\hline June & - & & - & & - & \\
\hline July & - & & - & & - & \\
\hline Total & 84 & 100 & 96 & 100 & 180 & 100 \\
\hline \multicolumn{7}{|c|}{$\begin{array}{l}\text { S1 - } 2004-2005 \text { season. } \\
\text { S2 - } 2005-2006 \text { season. } \\
\text { ST }-2004-2005 \text { and } 2005-2006 \text { seasons. } \\
\text { The percentages have been rounded. }\end{array}$} \\
\hline
\end{tabular}

substantially decreased their fitness exposure time from $S_{1}(2075 \mathrm{~h})$ to $S_{2}(407 \mathrm{~h})$ and almost doubled their practice exposure time from $\mathrm{S}_{1}(3420 \mathrm{~h})$ to $S_{2}(6570 \mathrm{~h})$, which contributed to an increase in total exposure time from $S_{1}(7735 \mathrm{~h})$ to $S_{2}(9265 \mathrm{~h})$. Team 2 increased their fitness exposure time from $S_{1}(3005 \mathrm{~h})$ to $S_{2}(3895 \mathrm{~h})$, with a comparable decrease in practice exposure time from $S_{1}(5825 \mathrm{~h})$ to $\mathrm{S}_{2}(5075 \mathrm{~h})$. The result was similar total exposure time in $\mathrm{S}_{1}(11083$ h) and $S_{2}(11119 \mathrm{~h})$. Team 3 had similar fitness exposure time in $S_{1}$ $(960 \mathrm{~h})$ and $\mathrm{S}_{2}(990 \mathrm{~h})$, but showed an increased practice exposure time from $S_{1}(3090 \mathrm{~h})$ to $S_{2}(3770 \mathrm{~h})$. Furthermore, this team had a considerable increase in match exposure time from $\mathrm{S}_{1}(1824 \mathrm{~h})$ to $\mathrm{S}_{2}(2071 \mathrm{~h})$, which contributed to an increase in total exposure time from $S_{1}(5874 \mathrm{~h})$ to $S_{2}(6831 \mathrm{~h})$. Team 4 only reported the exposure data for $S_{2}$ - therefore no comparison can be made from $S_{1}$ to $S_{2}$, which would be a slight limitation when analysing this exposure time.

The exposure time per team showed that Team 2 had a considerably greater fitness exposure time than the other teams in both seasons, while still maintaining a higher-than-average practice exposure time per season, which seemed to be the focus of the other teams for both seasons. Moreover, in $S_{2}$ Team 2 maintained their total exposure time while increasing their fitness exposure time and decreasing their practice exposure time.

\section{Discussion}

The first important finding was that the injury incidence for provincial cricketers was $30 / 10000$ hours. This was greater than for West Indian provincial players ${ }^{4}(14 / 10000 \mathrm{~h})$ and West Indian provincial $(22 / 10000 \mathrm{~h})$ and Australian test $(23 / 10000 \mathrm{~h})$ teams. ${ }^{3}$ The South African provincial players also showed a lower injury incidence than

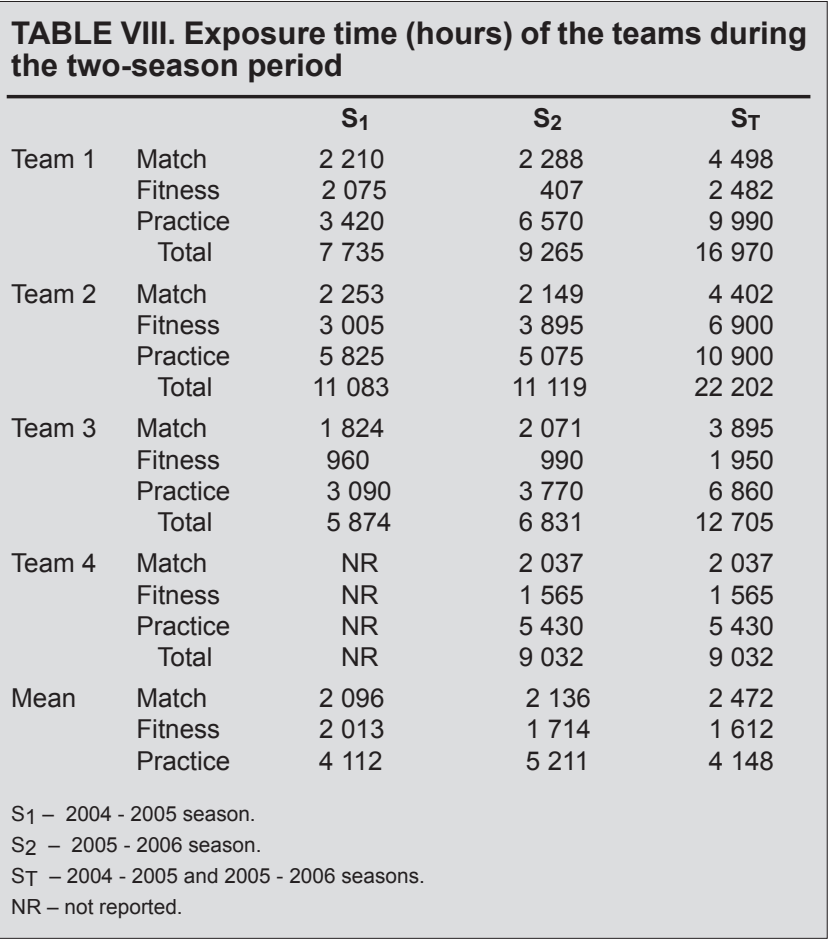

the West Indian test and ODI players (49 and 41/10 $000 \mathrm{~h}$ ). The South African results were similar to those of the Australian ODI players $(39 / 10000 \mathrm{~h})^{3,4}$ The injury incidence of the South African provincial players showed a decrease from $S_{1}(34 / 10000 \mathrm{~h})$ to $S_{2}(27 /$ $10000 \mathrm{~h}$ ). However, there was an increase in total exposure time which was mainly because of an increase in the training and practice exposure time. A possible explanation for this decrease in injury incidence could be that the match incidence of injury $(74 / 10000 \mathrm{~h})$ is far less than the training incidence of injury $(15 / 10000 \mathrm{~h})$.

Secondly, the injury prevalence in the South African provincial cricketers (8\%) was similar to that in the West Indian ODI (8\%) and Australian test (7\%) players and less than that in the West Indian test (11\%) and Australian ODI (10\%) players. ${ }^{3,4}$

However, there was an increase in injury prevalence from $S_{1}$ $(3 \%)$ to $S_{2}(8 \%)$, possibly as a result of a number of interdependent factors. It could be due to an increased number of matches being played from $S_{1}$ to $S_{2}$, resulting in an increase in match exposure time. There was an increase in the incidence of injury during the early part of the season, coinciding with an increased exposure time. This increased seasonal exposure time, with an emphasis on pre- and early-season activity, could have resulted in the increased incidence of injuries during the early part of the season. As the season progressed the incidence of injuries decreased, as did the match exposure time (242 $\mathrm{h}$ and $433 \mathrm{~h}$, respectively), during the middle and end of the season.

The increased number of injuries during the early part of the season could also be related to playing more first-class (4-day) cricket at the beginning of the season, with limited-over cricket matches being played towards the middle and end of the season with less match exposure time. During the longer version of the game the players tend to be relatively inactive for long periods of time before rapidly moving after the ball when fielding. Bowlers may be required to bowl multiple spells, sometimes accumulating over 20 overs in a day, compared with 4 - 9 over spells in limited-over cricket. This could have resulted in the large number of injuries during fielding and bowling, particularly during the early part of the season, and could have been further influenced by the fact that during the time period 
between first-class matches more emphasis was placed on rest with little time devoted to fitness maintenance activities.

A large number of injuries in the first season were first-time injuries of an acute nature, including impact injuries, particularly when batting, resulting in haematomas and other trauma injuries. However, in the second season there was an increase in recurring injuries from the previous season that was accompanied by an increase in acute-on-chronic injuries, the majority being muscle strains, tendinopathies and acute sprains. The above could also have been the result of the players returning to play without being fully rehabilitated and because of the nature of the injury sustained.

The primary mechanisms of injury were bowling and running to and sliding for the ball when fielding. Similar results were found in many of the West Indian players, where injuries were muscle strains caused by running after and picking up the ball and injuries to young fast bowlers. ${ }^{3}$ These activities all involve some kind of stop-start movement and/or change in direction of the whole body, requiring strength, agility and flexibility. In sports involving bouncing and jumping activities with a high intensity of a stretch-shortening cycle, a stretching programme significantly influenced the viscosity of the tendon, making it more compliant. Stretching may also be beneficial for injury prevention. ${ }^{7}$

Further investigation of the exposure time for Team 2 shows that they had the greatest fitness exposure time of the 4 teams, yet their injury prevalence was the lowest and decreased considerably from the first to the second season. One of the reasons for the decreased injury prevalence could have been that their fitness focused more on stretching, with dispersed activities of aerobic and core stability work. This increased fitness exposure time, particularly stretching activity, without the comparable decrease in practice exposure time could reduce the injury prevalence of cricket players and possibly the number of injuries from season to season. The other teams focused more on strength and aerobic activities with limited focus on stretching exercises.

\section{Conclusion}

Injury incidence and prevalence in South African provincial cricketers are similar to those in the West Indian and Australian studies. It would appear that injury prevalence can increase independently from injury incidence. Although the injury incidence was at an acceptable level, the injury prevalence still remains a concern and highlights the importance of receiving correct treatment and sufficient recovery time before returning to cricket. Increasing fitness exposure time, particularly stretching, could decrease the number of flexibility-related injuries. The correct fielding techniques and the number of overs bowled could be more closely monitored to decrease the injury prevalence.

\section{REFERENCES}

1. Leary $\mathrm{T}$, White $\mathrm{J}$. Acute injury incidence in professional county cricket players (1985-1995). Br J Sports Med 2000;34:145-147.

2. Stretch RA, Venter DJL. Cricket injuries - a longitudinal study of the nature of injuries to South African cricketers. S Afr J Sports Med 2002; 36: $270-275$.

3. Orchard J, James T, Alcott E, Carter S, Farhart P. Injuries in Australian cricket at first class level 1995/1996 to 2000/2001. Br J Sports Med 2002;36:270-275.

4. Mansingh A, Harper L, Headley S, King-Mowatt J, Mansingh G. Injuries in West Indian Cricket 2003-2004. Br J Sports Med 2006;40:119-123.

5. Orchard J, Newman D, Stretch R, Frost W, Mansingh A, Leipus A Methods for injury surveillance in international cricket. J Sci Med Sport 2005;8(1):1-14.

6. Orchard J. Orchard sports injuries classification system (OSICS). In: Bloomfield J, Ficker P, Fitch K, eds. Science and Medicine in Sport. 2nd ed. Melbourne: Blackwell, 1995:674-681.

7. Witvrouw E, Mahieu N, Danneels L, McNair P. Stretching and injury prevention: An obscure relationship. J Sports Med 2004;34(7):443-449. 